\title{
O estágio curricular e a didática na formação de professores: desafios e possibilidades
}

\author{
Cyntia Graziella G. S. Girotto* \\ Rosane M. de Castro**
}

\section{Resumo}

Neste artigo enfocamos aspectos das disciplinas do curso de Pedagogia "estágio curricular" e "didática" na formação de professores. O objetivo central é ressaltar, mediante apresentação do trabalho que realizamos em nossa prática docente nas disciplinas mencionadas, a importância da articulação entre a teoria e a prática na formação de professores e a fim de que o ensino na universidade não seja descontextualizado, mas enriquecido com as questões do cotidiano escolar. Nesse sentido, abordamos, inicialmente, aspectos do estágio curricular como elo mediador de aprendizagem, de articulação do currículo e de práticas e, nessa perspectiva, como um canal produtivo entre a universidade e a Educação Básica, ressaltando a necessidade do acolhimento da contribuição que cada uma das instituições, dentro de sua especificidade, deva oferecer nos cursos de formação. Na sequência, apresentamos aspectos da estrutura do trabalho que desenvolvemos com nossos alunos no estágio curricular na Educação Infantil. Finalmente, explicitamos os aspectos de uma didática voltada para a formação de professores da Educação Infantil e dos anos iniciais do Ensino Fundamental, centrada em narrativas de professores em serviço, sobre suas vivências e experiências docentes, em busca de novas sistematizações da e sobre a prática pedagógica, pelos próprios sujeitos.

Palavras-chave: formação de professores, estágio curricular, didática.

\section{The curricular training and the didactics in training of teachers: challenges and possibilities}

\section{Abstract}

In this paper we addressed aspects of the disciplines "Curricular Training" and "Didactics" in the Pedagogy Course in training of teachers. The main objective is to emphasize upon submission of the work that we do in our teaching practice in the mentioned disciplines, the importance of linking the theory and the practice in training of teachers so that the teaching in the university it is not decontextualized but enriched with the issues of everyday school life. In this

\footnotetext{
* Professora Doutora da Universidade Estadual Paulista Júlio de Mesquita Filho (Unesp), Faculdade de Filosofia e Ciências - Campus de Marília, Departamento de Didática, Marília, São Paulo.

** Professora Doutora da Universidade Estadual Paulista Júlio de Mesquita Filho (Unesp), Faculdade de Filosofia e Ciências - Campus de Marília, Departamento de Didática, Marília, São Paulo.
} 


\section{Cyntia Graziella Guizelim Simões Girotto - Rosane Michelli de Castro}

sense, we address, initially, the aspects of the Curricular training as a mediator link of the learning, of the articulation of the curriculum and of the practices and, in this view, as a productive conduit between the university and the basic education, stressing the need for the reception of the contribution that each institutions within its specificity, must provide in the training courses. In sequence, we present aspects of the structure of the work we do with our students in Early Childhood Education Curricular Training. Finally, are detailed the aspects of a Didactics for the teachers of early childhood education and for the early years of Fundamental Education, focusing on narratives of in-service teachers on their experiences teaching in search of new systematization of pedagogical practice and on by own teachers.

Keywords: training of teachers; curricular training; didactics.

\section{Estágio Curricular: elo mediador de aprendizagem, de articulação do currículo e de práticas}

Partimos do pressuposto de que um dos objetivos centrais do estágio curricular é constituir-se como um espaço de aprendizagem no processo de formação dos professores, ${ }^{1}$ isto é, entorno ${ }^{2}$ gerador de situações significativas, junto às disciplinas teóricas desenvolvidas nos cursos de formação, voltadas à produção de conhecimentos e com potenciais possibilidades de contribuir com o fazer profissional do futuro professor.

Desse ponto de vista, ao discutirmos as diferentes modalidades em que o estágio curricular pode ser realizado nas escolas-campo parceiras de formação (observação, participação, regência, dentre outras), salientamos que a aprendizagem somente se efetivará se as experiências vivenciadas nos estágios se constituírem como atividade, sendo discutidas e teorizadas num momento destinado a essa finalidade no interior do curso de formação inicial. Por isso, não basta ir à escola-campo. É necessário, em concomitância e/ou a posteriori, que as observações e/ou participações realizadas pelos alunos sejam consideradas no currículo do curso de formação; dentro de um espaço/ tempo, privilegiado para uma análise crítica e diálogo, na tentativa de integrar a realidade profissional com os aspectos estudados no curso. Em nossa realidade, buscamos contemplar tal pressuposto, convidando todos os professores do curso de Pedagogia, principalmente das turmas de terceiro e quarto anos séries em que se concentram a carga horária de estágio - a colaborarem em suas disciplinas. Nessa ação conjunta e colaborativa, o estágio vai se configurando como articulador da organização curricular; elo mediador que congrega disciplinas e práticas.

Como elo mediador de práticas, o estágio permite também ser um canal produtivo entre a universidade e a Educação Básica, reconhecendo, por 
um lado, a distância existente entre esses dois níveis de escolaridade; e, por outro, a não supremacia de uma instituição sobre a outra, evidenciando e acoIhendo a contribuição que cada uma das instituições, dentro de sua especificidade, deva oferecer à função da outra nos cursos de formação.

Essa reciprocidade demonstra a necessidade da articulação entre a teoria e a prática (PIMENTA, 2001), em função da formação de professores, a fim de que o ensino na universidade não seja descontextualizado, mas enriquecido com a problemática do cotidiano escolar, e nem a prática da escola seja, somente, fruto do senso comum, ou uma prática pautada pelo saber tácito, construído pela rotina, reprodução ou repetição das ações, mas fruto de uma ação crítica e reflexiva sustentada por um consistente referencial teórico.

Reafirmando a relevância do estágio como lócus de formação, aprendizagem, partilha de saberes e experiências entre os professores e os alunos que realizam os estágios, há, sem dúvida, a necessidade de estabelecer uma parceria produtiva entre o estudante e os profissionais experientes.

Contudo, concordando com Felício (2004; 2006), Felício e Possani (2008), Felício e Oliveira (2008), Piconez (1994) e Freire (2001), o estabelecimento de tal parceria com os profissionais das escolas-campo é uma situação delicada e, muitas vezes, conflituosa na realização dos estágios, pois essa relação ainda é marcada por inúmeras situações constrangedoras em que o estagiário é visto como aquele que está para "julgar" uma prática pedagógica profissional alheia. Sobretudo, porque a escola, principalmente a pública, apresenta-se tão vulnerável, fragilizada, insegura, que qualquer aproximação externa pode desencadear situações "mal-entendidas".

É interessante pensar nessa aproximação da realidade desenvolvida pelo estagiário na dimensão de um "olhar estrangeiro", ou seja, de alguém que está de fora, que veio de outro contexto, que não está condicionado ao cotidiano daquela prática, tendo, por assim dizer, condições diferenciadas para refletir sobre aquela realidade - numa metáfora, com humildade e muito respeito para com os "nativos da pátria local".

A inserção na realidade deve proporcionar a possibilidade de um olhar mais centrado e profundo sobre a complexidade que se instaura em torno do processo de ensino e de aprendizagem que se desenvolve na realidade educacional, impelindo os alunos a estabelecerem, em torno dessa "prática", um exercício de reflexão que contribua, por um lado, para a compreensão de tal realidade, e, por outro, para a apropriação de novos conhecimentos a partir da realidade da escola.

O "convite" feito aos estagiários é que desenvolvam um olhar crítico sobre a realidade que vivenciam no cotidiano escolar, tentando desvelar o cotidiano da instituição - como se colocassem uma "lente" de aumento para ver além 


\section{Cyntia Graziella Guizelim Simões Girotto - Rosane Michelli de Castro}

das obviedades, em busca não da aparência, mas da essência (KOSIK; 1976, ANDRÉ, 1995). Somente quando deixa de ser um exercício artificial e burocrático ou mera tarefa acadêmica, e torna-se verdadeira atividade, ${ }^{3}$ na acepção da palavra, de acordo com a perspectiva histórico-cultural, grande parte do alunado passa a ressignificá-lo, trazendo a marca de entorno fundamental a sua própria formação.

\section{O estágio curricular da Educação Infantil: tateios e reflexões, em busca de possibilidades}

Iniciamos este tópico com uma declaração espanhola, que expressa os eixos centrais a dirigir os nossos tateios e reflexões no/para/com o estágio curricular da Educação Infantil.

1) A educação, aquela que nos faz humanos [...] o dever de educar é inerente à espécie humana [...] a educação [...] é a promoção da humanidade em cada pessoa.

2) A educação, uma responsabilidade pública [...]

3) Uma criança rica e reconhecida pela sociedade. A nova educação [...] se fundamenta em uma imagem positiva da criança como sujeito ativo desde o nascimento, como um cidadão com um lugar na sociedade, um protagonista sujeito de direitos a quem a sociedade deve respeitar e dar apoio.

4) As famílias, protagonistas essenciais [...]

5) Contextos educativos públicos [...]

6) A escola [...] uma mudança do significado de educação e escola: a educação no sentido mais global e holístico, sem separar cuidado e educação, razão e emoção, mente e corpo.

7) Os educadores. A nova educação pede um forte compromisso dos educadores, como mediadores das crianças em todo processo da educação.

8) Currículo, conhecimentos e aprendizagem. A nova educação [...] organiza os conteúdos a partir daquilo que é absolutamente necessário à educação da primeira infância [...]

9) A avaliação. [...] considera a avaliação como um processo continuado, um processo participativo e democrático, que conta com todos os protagonistas da comunidade.

10) Participação e governo. [...] define a participação como um valor essencial. A expressão democrática de uma responsabilidade coletiva e um interesse público. (DECLARACIÓN DE LA 40 ESCUELA DE VERANO DE ROSASENSAT/ Barcelona, 14 de julho de 2005 - tradução nossa). 
Esses dez pontos de uma visível utopia compartilhada traduzem, também, o nosso compromisso de professores-formadores, permitindo vislumbrar, nessa luta, uma renovada esperança no futuro.

Nesse sentido, nas aulas teóricas de estágio supervisionado e prática de ensino o que se busca é a vivência das práxis, ou seja, organizá-las de tal forma a garantir, também em sala, aquilo que almejamos para com as crianças, ou seja, a ter o que se estabelece como objetivos para os pequenos e pequenininhos, primeiro para a própria formação dos educadores da infância.

Desse ponto de vista, nossos encontros se estruturam a partir dos princípios das escolas italianas de Reggio Emilia, do Instituto Loczy (Hungria), das experiências espanholas (Instituto Municipal de Barcelona), da Metodologia de Projetos da francesa Josette Jolibert e colaboradores, e de algumas técnicas Freinet. Dentre elas, algumas mais antigas, todavia, atuais - todas elas exemplos notáveis da relação interativa, teoria-prática, que por sua vez, sendo do conhecimento dos educadores da infância, podem trazer nova orientação para a prática.

As contribuições de Freinet (1973a; 1973b; 1974) são inúmeras. Suas técnicas foram e ainda são inovadoras; partem do dia a dia da sala de aula para a construção de um aprendizado significativo, garantindo o sentido da presença das crianças na escola. As técnicas Freinet como a aula passeio; a imprensa; o texto livre; o livro da vida; a correspondência escolar; o jornal escolar e o jornal de parede; a roda de conversa; os álbuns, os livros, os jornais; e os projetos permitem ao educador percorrer um caminho no qual a reflexão da própria prática é inerente ao processo, pois as técnicas apoiadas nos princípios freinetianos - na cooperação, na livre expressão, no trabalho e na autonomia - não são meras regras isoladas, exigindo do professor uma compreensão sobre o processo de ensino como colaborativo, coletivo, compartilhado, coparticipativo; sendo o professor o criador de elos mediadores da cultura humana para a aprendizagem da criança.

Quem visitasse, à época de Freinet, sua escola poderia encontrar muito do que se alegrar, sobre o que refletir; como quem conhece de perto a experiência italiana, espanhola, húngara com a Educação Infantil também o têm, e/ou as experiências um pouco isoladas no Brasil, que, inspiradas nessas histórias de sucesso, persistem, e nos dizem muito de seus pressupostos teórico-metodológicos, ainda vivos, capazes de muito nos ensinar.

A experiência dos educadores italianos demonstra, no desenvolvimento de seu programa pedagógico, a importância educacional dos espaços, tempos e materiais bem pensados, planejados e articulados (JUBETE, 2005). A partir de premissas como "As crianças devem sentir que toda a escola, incluindo espaços, materiais e projetos, valoriza e mantém sua interação e comunicação" (RINALDI apud EDWARDS; GANDINI; FORMAN, 1999, p.148) foram criados 


\section{Cyntia Graziella Guizelim Simões Girotto - Rosane Michelli de Castro}

modos de tornar o espaço mais do que apenas local útil e seguro onde é possível passar horas ativas, mas entorno para a humanização, fonte de desenvolvimento (VYGOTSKY, 1935, p. 20).

Dada nossa história de educação "pré-escolar" e escolar longa de tradição, conservação e reprodução, como, por exemplo, as do ensino da leitura e de escrita dirigidas a práticas prescritivas e normativas calcadas na grafia e na consciência fonológica, já para os pequenos, é preciso ter coragem para resgatarmos os pressupostos dessas experiências, em busca de superação, mesmo que consideremos as diferenças institucionais e culturais de nosso país para com a origem de tais experiências. Não se trata de imitá-las, mesmo porque nenhuma prática ou proposta é idêntica: tempos, espaços, idiossincrasias dos sujeitos são outros. Nossas vivências têm nos proporcionado ir além dos modismos, considerando que nossa configuração social é diferente, de modo que nossas apropriações, objetivações e batalhas também precisam ser outras.

Diante desse esboço, o trabalho realizado na disciplina de estágio curricular mediante aulas dialogadas inicia-se com uma roda de conversa, em que é feita a leitura do livro da vida, pelo narrador do penúltimo encontro-aula, resgatando o estudado na ocasião. Pontuando-se, ainda, o objetivo da aula daquele dia e já estabelecendo a rotina de trabalho. A conversa continua comentando-se sobre a semana, textos estudados, estágios realizados, casos e episódios de ensino a serem relatados, e a escolha das notícias a constituírem o jornal da turma.

Na sequência temos uma metáfora (um vídeo, ${ }^{4}$ uma poesia, um livro de literatura infantil, um conto, uma história, um pensamento, uma música, uma sequência de fotos de crianças em atividade no berçário, com a Cesta dos Tesouros $^{5}$ - o resgate de uma visita a uma instituição de Educação Infantil, etc.) que foca o conceito central a ser trabalhado na unidade de estudo em questão, que, por sua vez, origina-se dos projetos de estudo organizados com as turmas, bem como do roteiro de observação de estágio.

O uso das metáforas tem se configurado com um elo de ligação com a prática observada e/ou vivida, de acordo com as memórias de vida escolar de cada um.

Após, temos o estudo do texto teórico de base (sobre o qual cada aluno entrega, antecipadamente, à aula, sua síntese pessoal) e o compartilhar de outros de apoio que aprofundam as questões debatidas. Ao final, reserva-se um tempo para a roda de leitura, em que os alunos, por meio de um baú de livros, disponibilizado pela professora, selecionam a sua leitura para o momento, enquanto a docente atende individualmente alguns alunos, na sessão de dúvidas, e/ou orienta coletivamente por grupos de interesse. Por fim, é estabelecido quem será o narrador daquele encontro e que levará o livro da vida para casa, a fim de se fazer o relato do dia - dessa forma, por meio desse tipo de 
documentação pedagógica, cria-se a possibilidade de síntese do trabalhado, de memória para grupo e de avaliação sobre o vivido. ${ }^{6}$

\section{A didática e os saberes das práticas docentes na formação de professo- res}

Ao encontro da articulação entre a teoria e a prática (PIMENTA, 2001), em função da formação de professores e a fim de que o ensino na universidade não seja descontextualizado, mas enriquecido com a problemática do cotidiano escolar, também, na disciplina de didática do curso de Pedagogia, temos procurado orientar os processos formativos de nossos alunos, futuros professores, tendo como aspecto básico para a mediação entre realidade e pensamento a ação prática dos professores em serviço. Tal formulação tem como referencial as teorizações de Martins (2004) sobre o que denomina como pesquisa-ensino, ou seja, um modelo em que os processos formativos mencionados seriam trabalhados por meio de três níveis: realidade, ação sobre a realidade e pensamento decorrente dessa prática, ao invés do que usualmente têm-se trabalhado, apenas mediante realidade/pensamento (MARTINS, 2004, p. 52).

Desse ponto vista teórico-metodológico, acreditamos que a didática, ao pretender orientar os processos formativos de professores, deve ir ao encontro da expressão de suas ações práticas, para a produção de conhecimentos relativizados, entendidos a partir das circunstâncias, dos sujeitos e dos lugares sociais daqueles que os elaboram e divulgam.

Essa compreensão é responsável pelas opções metodológicas feitas para a proposição da nossa ação docente e de projetos de pesquisa e de extensão, prioritariamente a denominada história oral, valorizadora das narrativas dos sujeitos envolvidos, centrada nos sujeitos, em suas narrativas das situações vividas, nas experiências, na história (MEIHY, 2000). Entretanto, como muito bem explicita Teixeira (2004, p.159), é preciso que seja esclarecido que não se trata de uma metodologia voltada apenas aos estudos do passado, "[...] mas também do tempo presente, do contemporâneo":

Nesse sentido, temos convidados professores em serviço na Educação Infantil e no Ensino Fundamental para participarem das nossas aulas e dos nossos projetos, especialmente em instituições de Educação Infantil e de Ensino Fundamental, juntamente com os futuros professores em processo de formação inicial do curso de Pedagogia da Faculdade de Filosofia e Ciências - Unesp/ Campus de Marília. Os professores em serviço nas escolas são chamados a falar sobre o que pensam e sobre as situações que vivem com outros docentes, em que trocam experiências pedagógicas. Após, tanto os professores em formação continuada quanto aqueles em formação inicial são convidados a sistematizarem coletivamente o conhecimento acerca dos processos e ações educativas que ocorrem nas escolas, e a proporem hipóteses de ações para 0 aprimoramento desses processos e ações. 


\section{Cyntia Graziella Guizelim Simões Girotto - Rosane Michelli de Castro}

Dos núcleos básicos de ações docentes que se relacionam com o campo da didática privilegiamos investigar, inicialmente, aspectos do processo de ensino e de aprendizagem, que é o ponto de partida para análise da ação docente e ponto de retorno para constante sistematização. Sendo assim, as investigações ocorrem quanto:

- à dimensão cognitiva, socioeconômica, afetiva e cultural dos alunos;

- as condições de vida e de trabalho, formação e práticas dos professores;

- a escolha de atividades de ensino diferenciadas e de técnicas variadas;

- a relação educador/educando: disciplina e indisciplina;

- ao planejamento e avaliação do ensino e da aprendizagem.

A primeira etapa consiste na coleta das narrativas dos sujeitos selecionados, mediante aplicação de entrevistas, do tipo semiestruturadas, e com o auxílio de algum aparelho que possui gravador. Posteriormente são feitas as transcrições dessas entrevistas ipsis litteris. Nesse momento, chamamos a atenção para a necessidade de se buscar uma percepção aguçada, por parte dos pesquisadores, dos aspectos anteriormente relacionados.

Numa outra etapa, o trabalho desenvolvido é o de identificação de unidades de análise, a partir das quais se torne possível a elaboração de eixos de análise com tais unidades, para, numa última etapa, realizarmos o trabalho de análise e interpretação mais amplo.

Para o desenvolvimento da primeira etapa do trabalho, propriamente dito, são realizadas com os professores em formação inicial do curso de Pedagogia leituras e discussões de uma bibliografia básica, ${ }^{7}$ acerca das formulações teóricas da vertente metodológica privilegiada - história oral -e, particularmente, sobre as narrativas e suas exigências e implicações para um trabalho de investigação sobre práticas e concepções docentes.

Posteriormente a preocupação centra-se nas entrevistas, considerando que se trata do instrumento privilegiado para a obtenção dos dados e informações. Particularmente com relação à entrevista do tipo semiestruturada, ressalta-se o fato de ela constituir-se em um instrumento que possibilita a obtenção dos dados e informações em maior profundidade e abrangência, diferentemente da estruturada com questões mais fechadas.

$\mathrm{Na}$ etapa posterior a das transcrições ipsis litteris das narrativas, a preocupação é de efetuar a passagem do estágio oral para o escrito, o mais fielmente possível, visto que nessa fase importou dar visibilidade às narrativas. Nessa etapa consideramos a utilização de um aparelho que sirva de gravador, a 
fim de que seja permitido o reexame do conteúdo das entrevistas, por várias vezes e de maneira minuciosa.

Entretanto, conforme Meihy (2000, p. 89), é certo que, mesmo com todos os esforços empreendidos, a transcrição de palavra por palavra, como a que foi buscada, não corresponderia à realidade da narrativa. Isso porque "[...] uma gravação não abriga lágrimas, pausas significativas, gestos, o contexto do ambiente [...] Além do mais, há as entonações e as palavras de duplo sentido." (MEIHY, 2000, p. 89).

Numa etapa final, o trabalho realizado é o de análise e interpretação dos dados e informações obtidas com as narrativas.

O primeiro momento é o de identificação de unidades de análise, a partir das quais é possível construir categorias com tais unidades, para posterior trabalho de análise e interpretação das narrativas dos professores entrevistados.

Nesse momento de análise, são idas e vindas da teoria apreendida pelos professores em formação inicial, e trabalhada coletivamente com os professores em serviço, ao material de análise e vice-versa e, finalmente, são construídas eixos de análise que parecem mais completos e satisfatórios em face dos objetivos propostos. Tais procedimentos são previstos num trabalho de análise de conteúdo conforme explicitado por Bardin (1977). Concomitante com esse último trabalho, são formuladas algumas ações e apresentadas pelo grupo dos sujeitos envolvidos para um possível repensar, recriar, ressignificar do trabaIho didático-pedagógico das escolas. Tais ações são apresentadas, sobretudo, mediante projetos de extensão, sugeridos para o aprimoramento das situações das escolas e das práticas docentes.

Além do núcleo de ação docente com o qual se iniciam os trabalhos, como já mencionado, outros núcleo de ações docentes que se relacionam com o campo da didática também são alvos de investigação, a saber:

1) Os recursos e as formas de organização do trabalho pedagógico na escola. Este núcleo envolve investigação quanto:

- à estrutura física - localização, instalação, recursos materiais e humanos, número de turnos de funcionamento, salas de aula em funcionamento e de alunos por sala;

- a organização do trabalho escolar - estrutura administrativa e pedagógica, relações de poder, formas e processos de participação e gestão;

- ao corpo discente - nível socioeconômico-cultural; 
- ao corpo docente - situação funcional, tempo de serviço, tempo na escola;

- aos problemas enfrentados pela escola.

2) As perspectivas teóricas às quais as práticas dos professores encontram-se vinculadas. Este núcleo permite a reflexão sobre práticas como sendo resultados de orientação teórica específica que, por sua vez, estão presentes em um projeto político próprio. Envolve investigação quanto:

- à concepção de homem, de mundo, de conhecimento;

- ao papel da escola;

- aos pressupostos de aprendizagem;

- a concepção de ensino.

3) As propostas para reconstrução da prática pedagógica. Neste núcleo cabem todas as proposições para reconstruir o ensino de sala de aula e a prática pedagógica da escola. Tais proposições podem ser elaboradas e discutidas ao mesmo tempo em que se faz a análise crítica das situações de ensino e das condições de trabalho na escola, mas podem também envolver propostas mais amplas de reconceitualização total da prática docente. Envolve investigação quanto:

$$
\begin{aligned}
& \text { - a gestão democrática; } \\
& \text { - ao trabalho coletivo; } \\
& \text { - a construção do projeto pedagógico. }
\end{aligned}
$$

Ainda, após a finalização dos trabalhos, o conjunto dos envolvidos é motivado a produzir textos sínteses com os resultados obtidos. Sobre esse trabalho cabe ressaltar que, no plano técnico, são ainda maiores as exigências quanto às capacidades de invenção, de improvisação e de rigor na elaboração dos textos a fim de garantir, ainda que com a escrita de um conjunto de sujeitos, um texto coerente, coeso e compatível com os objetivos que se espera alcançar.

\section{Algumas considerações finais}

Perceber o estágio curricular como aspecto de articulação no currículo de formação atinge o ápice quando os alunos são capazes de transitar em diferentes direções, ou seja, levar da disciplina para o estágio e trazer do estágio para a disciplina, numa sequência que não obedece a uma ordem linear lógica. Para muitos estudantes trabalhadores, é por intermédio do estágio que ele experimenta uma primeira aproximação da prática pedagógica desenvolvida por professores nas escolas-campo. 
Associada a essa questão, os alunos consideram que a fundamentação teórica, para a realização das atividades de estágio, é de uma contribuição essencial, sobretudo pelo papel que a teoria exerce na formação profissional, oferecendo perspectivas de análises para, de um lado, compreender a realidade da Educação Infantil que se mostra cada vez mais complexa e, por outro lado, por contribuir para que a relação teoria-prática se constitua como um processo de práxis, a todo o momento, possibilitando que $o$ ato de fazer estágio tenha significado na formação inicial dos professores.

A socialização das experiências vivenciada no estágio, para os alunos, é considerada um momento muito importante no currículo. Primeiro, porque confere ao aluno o protagonismo da aula e o exercício do trabalho coletivo, do respeito, da escuta, da análise, e, principalmente, da ética para com o professor com o qual é realizado o estágio na escola-campo.

A possibilidade de construir conhecimentos com a prática do outro é uma aprendizagem, descrita pelos alunos como sendo uma mostra do que se deve e do que não se deve fazer. O saber fazer bem é assumido, pelos alunos, como sendo um "modelo", não a ser seguido tal e qual, mas que serve como uma referência à sua própria prática futura.

Ainda, gostaríamos de registrar algumas das reflexões realizadas à luz das formulações sobre os sujeitos praticantes dos cotidianos das escolas, suas vivências e o papel da didática como disciplina a contribuir para a formação do professor e, nesse sentido, como afirmam alguns pesquisadores, é que falar sobre as vivências dos docentes em situação de trabalho requer do pesquisador falar particularmente com esses docentes, numa fala impregnada de possibilidades de descobertas dessas várias vivências e de outras de outros sujeitos, particularmente, dos integrantes da comunidade escolar da qual se trata.

Observamos também que as questões vivenciadas pelos docentes e retomadas mediante as narrativas evidenciam outras possibilidades de reflexão e ação sobre a formação dos professores e sobre prática docente, o que um olhar apressado não possibilita.

Diante do trabalho que vem sendo realizado, é possível afirmarmos que há aspectos importantes para a formação do professor, dos quais a didática, como disciplina ou matéria do curso de Pedagogia, não pode eximir-se: a necessidade da análise privilegiando os saberes das práticas e o cuidado com os processos de análise e interpretação dos mesmos e suas articulações, a fim de que se possa identificar e situar temas de pesquisas que importam à educação, buscando entender em profundidade os saberes e os fazeres produzidos no cotidiano escolar.

Como últimas palavras, afirmamos o caráter de provisoriedade que tem norteado toda a nossa prática de professoras formadoras de outros profes- 
Cyntia Graziella Guizelim Simões Girotto - Rosane Michelli de Castro

sores, uma vez que acreditamos no processo de inconclusão, incompletude do ser, estar e se fazer docente, pois o homem é um ser inacabado e suas atitudes e obras também o são.

\section{Referências}

AMADO, J.; FERREIRA, M. de M. (Coords.). Usos e abusos da história oral. 4. ed. Rio de Janeiro: Editora FGV, 2001.

BARDIN, L. Análise de conteúdo. Lisboa: Edições 70, 1977.

BOSI, E. Memória e sociedade. Lembranças de velhos. São Paulo: T. A. Queiroz, 1979.

DECLARACIÓN DE LA 40 ESCUELADE VERANO DE ROSA SENSAT/BarceIona, 14 de julho de 2005.(mimeo)

EDWARDS, C.; GANDINI, L.; FORMAN, G. As cem linguagens da criança: a abordagem de Reggio Emilia na educação da primeira infância. Porto Alegre: ARTMED, 1999. 319p.

FELÍCIO, H. M. dos S. O estágio curricular na formação de professores: diversos olhares. Dissertação (Mestrado em Educação). Pontifícia Universidade Católica - PUC/SP, 2004.

. Dimensões do estágio no currículo de formação inicial de professores. Pensamento \& Realidade, São Paulo, v. 18, p. 91-102, 2006.

FELÍCIO, H. M. dos; OLIVERA, R. A. A formação prática de professores no estágio curricular. Educar em Revista, v. 32, p. 215-232, 2008.

FELÍCIO, H. M. dos; POSSANI, L. P. As implicações éticas do estágio curricular na formação de professores. Pensamento \& Realidade, São Paulo, v. 22, p. 29-42, 2008.

FREIRE, A. M. Concepções orientadoras do processo de aprendizagem do ensino nos estágios pedagógicos. Colóquio: Modelos e Práticas de formação Inicial de Professores, Faculdade de Psicologia e de Ciências da Educação, Universidade de Lisboa. Lisboa, Portugal, 2001. Disponível em: http:/ www.educ.fc.ul.pt/recentes/mpfip/pdfs/afreire.pdf. Acesso em: 22 set. 2010.

FREINET, C. As técnicas Freinet da escola moderna. Lisboa: Editorial Estampa, 1973a.171p.

Para uma educação do povo. Lisboa: Presença, 1973b. 213p.

A educação pelo trabalho. Lisboa: Presença, 1974. 232p.

JUBETE, M. Unos espacios y unos tiempos de socialización y aprendizaje. INFAN-CIA. Revista de la asociación de maestros Rosa Sensat.n. 92 julho/agosto. 2006. p.16-21. 
MARTINS, P. L. O. Princípios didáticos na ação docente: conhecimento como expressão da ação humana. In: ROMANOWSKI, J. P.; MARTINS, P. L. O.; JUNQUEIRA, S. R. A. (Orgs.). Conhecimento local e conhecimento universal: pesquisa, didática e ação docente. Curitiba: Champagnat, 2004. v. 1, p. 43-57.

MEIHY, J. C. S. B. Manual de história oral. 3.ed. São Paulo: Edições Loyola, 2000.

MELLO, S. A. Documentação pedagógica: uma prática para a reflexão. Encontro EducaSul: Pensando a infância e a educação das crianças de 0 a 10 anos numa perspectiva integrada. Florianópolis, 2005. (mimeo)

PICONEZ, S. C. B. et. al. A prática de ensino e o estágio supervisionado. 2 ed. Campinas: Papirus, 1994.

PIMENTA, S. G. O estágio na formação de professores: unidade teoria e prática? 4. ed. São Paulo: Cortez, 2001.

QUEIROZ, M. I. P. de. Variações sobre a técnica de gravador no registro da informação viva. São Paulo: T. A. Queiroz,1991.

SIMSON, O. R. de M. V. (Org.). Os desafios contemporâneos da história oral-1996. Campinas: Área de Publicações CMU/Unicamp, 1997.

TEIXEIRA, I. A. de C. História oral e educação: virtualidades, impregnações, ressonâncias. In: ROMANOWSKI, J. P.; MARTINS, P. L. O.; JUNQUEIRA, S. R. A. (Orgs.). Conhecimento local e conhecimento universal: pesquisa, didática e ação docente. Curitiba: Champagnat, 2004. v. 1, p. 153-165.

VYGOTSKY, L. S. O problema do entorno. 1935. mimeo.

Notas

${ }^{1}$ Neste texto, as referências aos professores e às professoras, alunos e alunas e a estagiários e estagiárias, sejam de modo específico ou não, foram feitas utilizando-se o substantivo correspondente masculino.

2 Por entorno compreendemos, com base em Vygotsky (1935), que se trata de fonte de desenvolvimento e não apenas seu âmbito. No entorno se encontram as formas finais e ideais do desenvolvimento a ser alcançado pelo sujeito em seu processo de humanização.

${ }^{3} \mathrm{O}$ conceito de atividade é aqui utilizado com base na teoria da atividade humana de A.N. Leontiev e Davídov (1988) que explicita a estrutura e o funcionamento da atividade da aprendizagem, cujos elementos são o desejo, as necessidades, os motivos, os objetivos, as ações e as operações. A atividade de aprendizagem, pela qual são internalizados os conhecimentos e os modos apropriados de adquiri-los, constitui-se no meio cognitivo indispensável para a realização de outras atividades (a comunicação, o jogo, o trabalho, o esporte, a arte, etc.). Nesse sentido, a necessidade e o motivo de aprender referem-se à obtenção dos meios de internalizar conhecimentos teóricos para o aluno se relacionar com o mundo e consigo mesmo.

${ }^{4}$ São vários os DVDs que buscamos apresentar: experiências de instituições alemãs, húngaras, italianas, espanholas, inglesas, bem como brasileiras, como algumas paulistas, gaúchas, e paranaenses. 


\section{Cyntia Graziella Guizelim Simões Girotto - Rosane Michelli de Castro}

${ }^{5}$ Cesta dos Tesouros é o nome sugestivo dado por Elinor Goldschmied para uma forte, rasa e resistente cesta, que contém uma matriz de todos os dias com objetos naturais que, predominantemente, não devem ser de plástico, pois esses são muito semelhantes em muitos aspectos: suaves, inodoros e não têm gosto ou definição natural. A maioria dos objetos são os adultos que usam, ou estão no nosso ambiente natural. A cesta dos tesouros deve conter, portanto, objetos que variam em tamanho, peso, textura, temperatura, cor, sabor e som. Assim, os objetos devem ser escolhidos pelo seu valor para estimular um ou mais dos cinco sentidos. Bebês e crianças pequenas, naturalmente podem explorar os objetos na cesta com os seus sentidos para descobrir o que é, o que faz, e como ele pode ser manipulado. Segundo sua criadora, há a possibilidade de fazê-los entrar em um mundo de descoberta, surpresa, encontro social e de comunicação. Para Elinor Goldschmied, como os bebês sugam, agarram, tocam e sentem os objetos, esses comportamentos promovem o ensaio de seus primeiros aprendizados.

${ }^{6}$ Dessa forma, os alunos vão se apropriando de saberes teórico-metodológicos da docência, nesse caso, de uma forma de documentação pedagógica, que pode servir, na ação futura desse educador da infância, de meio de escuta do professor em relação ao seu trabalho e uma estratégia auxiliar em relação à escuta das crianças. Desse ponto de vista, já há um ganho para a elaboração e implementação dos projetos regências, pois os alunos fazem uso dessas apropriações. Além disso, salientamos em aula o uso de outras formas de documentação pedagógica (diários de bordo, semanários, memorandos, dossiês, portifólios, etc.), compreendida, de acordo com Mello (2005), como uma estratégia de organização do trabalho docente, de reflexão sobre a prática pedagógica e de construção sistemática de conhecimento sobre a prática, ou seja, com a intenção de aprender com a prática e não registro para a burocracia da escola; não uma observação das crianças com o objetivo de avaliar seu desenvolvimento, mas com o intuito de estabelecer uma relação cada vez mais consciente do educador com sua própria prática e com a teoria que orienta essa sua prática. É um meio de aprender a detectar problemas, a enxergar os problemas, analisá-los e enfrentá-los.

${ }^{7}$ Amado (2001); Bosi (1979); Meihy (2000), Queiróz (1991); Simson (1997).

\section{Correspondência}

Cyntia Graziella Guizelim Simões Girotto - Avenida Hygino Muzzi Filho, 737, Campus Universitário, CEP 17525-950 - Marilia, São Paulo - Brasil - Caixa-postal: 420.

E-mail: cyntia@marilia.unesp.br - rosanemichelli@marilia.unesp.br 